\title{
6
}

\section{Using Cooperative Games for Faculty Development}

\section{Barbara J. Millis}

United States Air Force Academy

Learning through games has been going on for centuries. Faculty developers, however, are only now realizing the impact of well-structured and well-planned games. They not only "educate" engaged faculty members, but they can also motivate them. This chapter discusses the educational value of games, reveals their key underlying principles, and offers two examples of successful faculty development games (scavenger hunt and Bingo) that can be replicated on any campus.

\section{INTRODUCTION}

ames probably go back to the times when early homo-sapiens needed to Irelax after a strenuous mammoth hunt. Costello (1991) states that the earliest known game board, measuring only seven by three inches, probably can be dated between 4000-3500 BC. Found in a predynastic cemetery in ElMehasna, Egypt, it seems to be an early version of Senet, a backgammon-type game known through tomb paintings to be popular in ancient Egypt. Games have been found wherever humans gather and appear to have been adapted from culture to culture. For example, variations of the popular African strategy game, Mancala, have been found in East and West Africa, southern India, and Sri Lanka. Because of their competitive nature, games can have more sinister consequences, as in the Mayan and Aztec ball courts, but, for the most part, games typically appeal to the human love of play.

In fact, faculty developers who downplay individual competition and emphasize cooperation can capitalize on the team-building camaraderie of games as well as their potential to enhance learning. This chapter will explore some 
of the theory behind creative games and conclude with two specific games easily adapted for a number of faculty development opportunities.

\section{The Solid Educational Basis of Games}

El-Shamy (in press) defines a game as a "competitive activity played according to rules within a given context, where players meet a challenge in their attempt to accomplish a goal and win" (p. 21). She distinguishes a game from a simulation in that the latter often deliberately sets up an uneven playing field where players begin unequally or receive unequal treatment as the simulation progresses. Furthermore, unlike the fantasy worlds prevalent in some games, simulations often mirror real-life situations and encourage players to gain insights and/or to build their professional skills by making informed decisions.

Both games and simulations prove to be effective learning tools for several reasons. They reinforce many theories of educational development. Adult learning theory, for example, emphasizes self-directed, goal-oriented learning. When adult faculty members are invested in the subject matter and the game itself, they willingly support one another and master critical material such as the laws governing harassment in the workplace or university guidelines regarding diversity issues. Games also appeal to a variety of senses, particularly the visual, auditory, and kinesthetic, making them attractive to different types of learners. New developments in cognitive psychology emphasize the role of emotions in learning: Games create a positive association and also allow for the repetition and deeper processing that strengthens neural pathways. Further, they offer multiple opportunities for feedback on learning. Bransford, Brown, and Cocking (2000) emphasize that "students need feedback about the degree to which they know when, where, and how to use the knowledge they are learning" (p. 59). Many games offer opportunities for application with immediate feedback. As Thiagarajan (1999) reminds us, "Learners cannot master skills without repeated practice and feedback" (p. vii).

When cooperative elements are introduced, games can become even more effective. Having participants work in teams or pairs offers tremendous advantages over individuals competing against other individuals. The research base for this conclusion comes from a variety of disciplines, including cognitive psychology, as suggested above. Social interdependence theory, for example, postulates that individuals focused on a common goal (winning!) develop positive links. Kurt Lewin (1948) states that groups develop their interdependent identity through their common goals. Additionally, the anxicty level lessens when faculty members are able to pool their knowledge and resources. The social context heightens team motivation. Furthermore, the dialogue and 
discussion that occurs within the teams as they respond to questions encourages higher-order thinking such as analysis and evaluation. Feedback is enhanced by the immediate response of peer faculty members, leading to reflection and reinforcement.

\section{Principles Underlying Effective Game Use with Faculty}

In the classroom, instructors will assign students specific material to master prior to the game and then use the in-class game activity as a means of processing the information and providing feedback on whether or not it has been mastered. Occasionally, a game will precede formal instruction. Popular in corporations and training settings, games and simulations can also play an important role in developing positive interrelationships. Depending on the context and goal, when using games-usually in a workshop setting-faculty developers probably place equal weight on the social elements and the knowledge acquisition aspects. As with students, they are cognizant of key principles to optimize faculty learning and collegiality.

First, faculty participants must understand the relevance of any games to the workshop/university goals. Adult learners typically find games a waste of time if they perceive them to be frivolous. Faculty members in particular want a practical pay off: How can I use what I have experienced to further my own professional goals? Where, down the road, is the payoff, particularly in the classroom? Thus, any game activity must be preceded by clear explanations, including a careful rationale linked to overall goals.

Second, to ensure the educational value of games, faculty developers must match the level of challenge to faculty members' skills. A key credo here is "know thy faculty." During an orientation, for example, adjunct faculty new to the institution but with considerable experience will bring a variety of teaching/learning skills that can be tapped during an interactive game. Faculty totally new to teaching, on the other hand, can provide insights gleaned as learners but may not be able to augment them with teaching applications. Thus, games used during faculty development activities should offer challenges to all faculty participants, but the material should not be so complex that anyone feels overwhelmed-and thus gives up-or so simple that more knowledgeable faculty members lose interest in participating. In the latter case, sometimes faculty may relish the opportunity to help less experienced colleagues, but unless an event has been publicized with that goal, it is unlikely they will return to a second event out of pure altruism.

Third, to ensure continuing interest, games should be designed so that they are predicated on a combination of knowledge and luck. This premise is 
extremely important because otherwise one or two dominant faculty teams will discourage other teams from contributing their best efforts. If only knowledge is involved, then the same teams will repeatedly win, a disincentive for other teams to master the material prior to play (if applicable) or to continue trying to score if they fall behind. If the game is predicated only on luck, then obviously faculty members have no incentive to review the material prior to play. Because the luck of the draw determines the placement of markers, Bingo illustrates well this combination of knowledge and luck.

Fourth, to maximize learning, as mentioned earlier, games should be structured cooperatively. There can be competition between teams, but optimum learning will take place during the independent learning accomplished prior to the game (if this is possible with a faculty workshop) and the peer coaching that occurs as the team players agree on a response. Peer consultations reinforce learning or provide instantaneous feedback that learning was nonexistent, incomplete, or misguided. Plus, in a faculty development setting, these interactions cement team bonds and promote faculty interactions beyond the workshop itself (for a complete look at cooperative principles, see Millis \& Cottell, 1998).

Fifth, games must emphasize the targeted learning goals. Both faculty development facilitators and faculty participants must recognize that the greatest learning occurs during "processing" periods either as the game unfolds or at the end. A post-game instructor "debrief" helps faculty members learn what they have mastered or should have mastered. Too often, faculty development facilitators may gloss over these critical teachable moments in the spirit of fun or in an understandable desire to avoid preaching to the choir. This is a serious mistake-however unconscious-because the game then loses its relevance. As Sugar (1998) admonishes, "Know what you want your audience to learn or demonstrate during and after the game" (p. 8). Keen, dean of the faculty at Antioch College, states that the research on whether games promote learning is still mixed:

It depends on whether you're savvy about why you are doing it and if you take the time to work up to it and to debrief. The rule is to spend at least as much time debriefing as you spend playing the game; otherwise, what did you do it for? (qtd. in Rhem, 1996, p. 3)

Finally, any game-but particularly those used with faculty who look for role modeling and positive teaching examples-must be well organized and well structured so that the workshop does not founder on vague instructions and confusion. Obviously, the game playing period must be appropriate for 
the length of time available, and the physical environment must allow faculty teams to work together. There should be an intriguing blend of novelty and familiarity. That is why well-known formats-modified to maximize learning and collegiality-such as a scavenger hunt and Bingo are particularly effective.

\section{Two Games to Promote Faculty Learning and Collegiality}

\section{The Faculty Scavenger Hunt}

Like Bingo, a faculty scavenger hunt is highly versatile. It can be used for any number of faculty development activities, including graduate student workshops or new faculty orientations. The questions on the sheets given to participants are tailored to the appropriate content. Sometimes they can even reflect faculty input so that faculty developers are certain that experts in the room will be available. Prior to a faculty orientation, for example, the proposed form (Appendix 6.1) can be mailed to new faculty, asking them to indicate their confidence in responding to the given items. More important, new faculty should be asked what additional areas of expertise should be added.

To begin the play, each faculty member receives a form and listens to the instructions, which are also printed on the top of the form. Unlike traditional scavenger hunts where participants rush from person to person, frantically seeking signatures to complete their form, this faculty game emphasizes deep conversations and collegiality. Within the allotted time frame, usually $20 \mathrm{~min}$ utes or so, faculty are encouraged to engage in meaningful conversations with three colleagues who can exchange with them valuable insights about teaching. The faculty developer emphasizes, however, that there is no need to terminate valuable conversations because of an arbitrary time line. If two faculty members end up deeply engaged in an insightful give and take for the entire session, then that is perfectly fine. The parties involved share contact information-usually email addresses-which they each retain on their scavenger hunt forms.

As faculty mingle, the conversations are animated, intense, and totally collegial. Everyone has something to share. In fact, a problem for the faculty developer is getting everyone's attention for the concluding "awards ceremony."

The session concludes with a noncompetitive drawing that emphasizes collegiality. Faculty tear off the bottom portion of their form, which indicates their name, and place it in a designated container (they will have to be reminded to do this). The faculty developer then draws a slip and calls out the name of the lucky person. Up to three slips can be drawn in sequence (it adds a nice touch to have the "winner" draw the next slip). As their name is called, 
the designated faculty members then consult their signed scavenger hunt sheets and introduce in turn the colleagues they discovered as resource persons. These colleagues, who stand to be recognized, then-briefly-share their insights. Each cluster becomes, virtually instantaneously, a celebrated team. Teaching ideas abound, with many faculty ( 12 or more) receiving recognition from a roomful of peers. The "prizes" can be merely the recognition itself or they can be token awards (candy bars, Post-it Notes, Kleenex packets, etc.) which are claimed by each "team."

Faculty developers may wish to emphasize the classroom applications of a scavenger hunt. It can be used, for example, as a first-or second-day-of-class icebreaker. The scavenger hunt form can contain questions based on information previously collected from students (find someone who was born in Maryland/likes country-and-western music/skis) or on class-related topics (find someone who has read The Red Badge of Couragelinvests in the stock market/considers themselves a Democrat). It can also be used as a way to identify "study buddies" prior to an exam (find someone who can explain clearly the principle of momentum/the symbolism in Moby-Dick the laws of supply and demand).

A faculty scavenger hunt is relatively easy to set up and conduct. More demanding are faculty development games such as Bingo.

\section{Bingo}

Bingo offers a game format easy to adapt to many faculty development needs. Bingo sheets can be created using the "Table" option on most word processing packages. Alternatively, Sugar (1998) of the Game Group has developed a set of reusable materials for a variation of Bingo called QUIZO. Bingo, often classified as a "frame game" or a "matrix game," is easily adapted to virtually any faculty development scenario where there is sufficient time for meaningful execution. If this game is used as a faculty development activity, then it is essential to also emphasize its classroom applications, such as its use for a viable, engaging review for a midterm or final examination.

Bingo becomes valuable for faculty development particularly when there is a core body of knowledge to both learn and apply. The game works best when participants come prepared to display and to share their knowledge. When a handbook is involved, for example, faculty not only study it, but they become even more involved by submitting creative Bingo questions prior to play. Thus, suitable topics might include sexual harassment laws, procedures, and case studies. A Bingo game could also be predicated on topics such as accommodations and modifications for individuals with disabilities. Perhaps 
one of the most effective uses of Bingo would be during a new faculty orientation where questions came from the faculty handbook. Too often new faculty have little time to read-let alone absorb-the esoteric, but often critically important "bureaucratese" in the handbooks. Thus, in a typical college/university orientation, a series of well-meaning, earnest administrators typically lecture on far-from-stimulating topics such as parking regulations, book orders, or student services. Bingo offers a refreshing alternative that virtually ensures greater retention. When new faculty receive their invitation to attend the orientation, they also receive important material such as the faculty handbook. However, their invitation also includes an instruction sheet clearly announcing the Bingo game and charging them to submit via email two (or more) well-crafted questions (Appendix 6.2). The instructions must clearly model the type of question requested, including examples, and also provide the format for submission. Faculty must submit one factual question, not a "nitpicky," irrelevant fact, but something important for all new faculty to know. For example, they might ask the location of the student counseling center, the three steps needed to obtain a parking sticker, or the name of the college/university president. The second question must involve multiple possible responses and promote higher-order thinking. Faculty, in fact, could be encouraged to write one-paragraph case studies. Typical examples might be "You are teaching an adult education class in the evening and during the break a student approaches you and confesses that he is dyslexic. He wonders if he might have some special considerations, particularly during the exam periods. How do you respond?" or "You are in your third week of teaching for IU, and you notice that students tend to be disrespectful. They eat during your class, read newspapers, accept cell phone calls, etc. What can you do to turn this situation around?"

Ironically, some faculty members need to be coached on question writing. But, this coaching also gives them a powerful incentive to strengthen their own student-directed questions in the classroom or for distance learners. Faculty tend to make their questions too rigid for the Bingo format. They need to allow for some "wiggle room" (e.g., not, "Give verbatim the university's policy on sexual harassment," but, "Paraphrase the university's policy on sexual harassment"). They also need to learn to realistically quantify answers (c.g., not "List the seven steps in a student grade appeal," but, "List three of the seven steps in a student grade appeal"). A typical entry would look like this: 


\section{Factual Question}

Define plagiarism

Name: Teacher Doe

Answer: To steal or pass off the words or ideas of another as one's own, without crediting the source.

Source: Faculty Handbook, p. 77.

Learning to pose viable, cogent questions is a valuable skill in and of itself. For example, a Nobel prize-winning physicist, Isidor Rabi, credits his mother with prompting him to value the questions he asked above the answers he gave. When he returned from school, she would never ask him what he learned that day. Instead, she would ask, "What good questions did you ask today?" (Barell as qtd. in Costa \& O'Leary, 1992, p. 59).

Faculty developers play a critical role in evaluating and categorizing the faculty-submitted questions. They eliminate any weak or inaccurate ones. They also add any significant questions that will help faculty members learn critical material. Faculty developers rank order the questions within the two categories (factual and open-ended) so that the most valuable questions will occur early in the play. They cut and paste the questions to a document that will later to be given to faculty members-or posted to a convenient web site-as a useful information sheet.

To use the questions during play, faculty developers enlarge the fonts to prepare transparencies. At the top of the transparency appears the question and the person submitting it. Space between the faculty member's name and the answer that follows it allows the answer to be easily covered when the question is posed.

Instructors purchase needed supplies: Skittles or M\&Ms for the markers (seasonal markers can be candy corn or Valentine hearts), and candy barslarge and snack sizes-for the prizes (healthier prize alternatives can be bags of pretzels, cocoa packets, ballpoint pens, etc.).

To play the game, the faculty developer pairs the participants (if there is an uneven number of participants, triads can be formed). Although most faculty members know the object of Bingo (five markers in a row in any direction) and the rules of play, it is important to explain the procedures so that anyone unfamiliar with Bingo will not feel compromised or inept. Each pair 
receives markers and two colored work sheets (as an example, green for the factual; gold for the higher level, open-ended questions) where they record their answers and if they were right or wrong. They can also note the space where the marker is to go. An abbreviated work sheet looks like this:

\section{Factual Questions}

Faculty Pair or Trio:

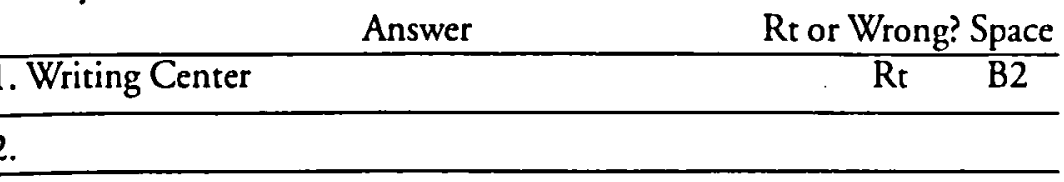

The faculty developer then poses the questions in sequence within each category, giving sufficient time based on their complexity. To make the game faculty-centered and to allow faculty members to receive feedback on the viability and fairness of their questions, the faculty member who submitted the question is the expert/arbitrator who decides what alternative answers are acceptable. The most important questions, of course, are the open-ended ones, particularly if they involve mini-case studies that will prompt meaningful discussions. Thus, it is important to allow sufficient time for ideas to unfold.

Pairs with correct answers place a marker on the designated square (e.g., $B 3$ or $G 1$ ). The square is determined by having the pairs in turn draw a Scrabble tile or a homemade variation (B,I,N,G,O) and roll a die (they roll again if a six emerges or faculty developers can purchase ten-sided die with only five numbers at novelty shops).

Pacing is very important. The factual questions speed up play and the higher-order thinking questions, as indicated earlier, lead to valuable discussions. Thus, always mindful of the clock, a savvy Bingo facilitator will offer frequent open-ended questions for their learning value but speed up play with factual questions. This process is facilitated by having the transparences, sorted in order of their significance, on either side of an overhead projector. Faculty developers comfortable with computer projections can toggle between the two types of questions.

The first pair (often there will be ties) to cover five contiguous squares in any direction declares "Bingo." After the two (or sometimes three) faculty members select a prize, they then clear their board and continue playing until 
the time period ends. In a one-hour session, it is theoretically possible for every pair to become "winners."

There are many reasons to use a Bingo game format, particularly for new faculty orientations. Because faculty submit in advance questions for which they are responsible, they are far more likely to read and reflect on the desired material. Furthermore, the very process of framing questions and later receiving feedback on their value, efficacy, and fairness encourages faculty members to concentrate on a useful teaching skill. Bingo also has assessment value on a different level after the orientation session concludes. The worksheets completed by faculty pairs during play should not be discarded. Reviewed collectively, without trying to single out individuals, they offer the faculty developer -and other administrators-valuable insights into what faculty members know and do not know. They also uncover important misconceptions that might be addressed on other occasions.

Bingo games keep faculty members actively engaged with the material, thus increasing the likelihood of their remembering it. Enthusiastic and energetic, like students, they often "high-five" each other when they get a correct answer. They listen attentively to the answers and suddenly care about the material, even arcane but critically important details, such as how to prepare a proposal for the institutional review board committee.

The Bingo format used during faculty development activities models positive teaching approaches. It emphasizes what faculty should be attempting to do in their own classes and provides a concrete take-away that can be easily adapted for classroom use, particularly when used as a review for a midterm or final.

Best of all, Bingo games build faculty collegiality. The pairs who work together develop personal bonds and the whole-group discussions over the open-ended questions allow faculty to engage in meaningful conversations that would likely not occur in less structured settings.

\section{Conclusion}

The word "game" carries with it a certain amount of "baggage" for many educators who may echo Ms. Trunchbull's credo in the movie Matilda: "If you are having fun, you are not learning." Other instructors, on the contrary, have found that students become engaged in learning through carefully structured, highly interactive game formats such as Jeopardy. Similarly, faculty expecting passive lectures during faculty development events usually welcome the interactive collegiality prompted by well-organized games. Realistically, there will be the occasional curmudgeon, but by and large, if the game is introduced 
well-with an emphasis on its learning potential-most faculty members become eager participants. Making the games cooperative enhances both faculty involvement and their learning. Besides promoting both learning and collegiality, games can be wonderfully satisfying for faculty developers who welcome opportunities to exercise their creativity.

\section{REFERENCES}

Bransford, J. D., Brown, A. L., \& Cocking, R. R. (Eds.). (2000). How people learn: Brain, mind, experience, and school. Commission on Behavioral and Social Sciences and Education National Research Council. Washington, DC: National Academy Press.

Costa, A. L., \& O'Leary, P. W. (1992). Co-cognition: The cooperative development of the intellect. In N. Davidson \& T. Worsham (Eds.), Enhancing thinking through cooperative learning. New York, NY: Teachers College Press.

Costello, M. J. (1991). The greatest games of all times. New York, NY: John Wiley and Sons.

El-Shamy, S. (in press). Training games: Everything you need to know about using games to reinforce learning. Sterling, VA: Stylus Press.

Lewin, K. (1948). Resolving social conflicts. New York, NY: Harper Press.

Millis, B., \& Cottell, P. (1998). Cooperative learning for higher education faculty. Phoenix, AZ: Oryx Press.

Rhem, J. (1996). Urgings and cautions in student-centered teaching. The National Teaching of Learning Forum, 5(4), 1-5.

Sugar, S. (1998). Games that teach: Experiential activities for reinforcing learning. San Francisco, CA: Jossey-Bass.

Thiagarajan, S. (1999). Teamwork and teamplay: Games and activities for building and training teams. San Francisco, CA: Jossey-Bass. 


\section{Contact:}

Barbara J. Millis

Director, Faculty Development Center for Educational Excellence

United States Air Force Academy

2354 Fairchild Dr.

Suite 4 K25

USAF Academy, CO 80840

Voice (719) 333-2549

Fax (719) 333-4255

Email Barbara.millis@usafa.af.mil

Barbara J. Millis received her $\mathrm{PhD}$ in English literature from Florida State University. The former Assistant Dean of Faculty Development at the University of Maryland, University College, she frequently offers workshops at professional conferences (AAHE, Lilly Teaching Conference, etc.) and for various colleges and universities. She publishes articles on topics such as cooperative learning; classroom observations (she was a FIPSE Project Director on this topic); the teaching portfolio; microteaching; syllabus construction; program, course, and classroom assessment/research; peer review; focus groups; and academic games. She co-authored Cooperative Learning for Higher Education Faculty with Philip Cottell (Oryx Press, 1998). In 2002, she co-authored Using Simulations to Promote Learning in Higher Education with John Hertel (Stylus Press). In 1998, she received the United States Air Force Academy's prestigious McDermott Award for Research Excellence in the Humanities and Social Sciences and the Outstanding Educator Award. After the Association of American Colleges and Universities (AAC\&U) selected the Air Force Academy as a Leadership Institution, she began serving in 2001 as a liaison to the AAC\&U's Greater Expectations Consortium on Quality Education. 


\section{APpendix 6.1}

\section{Faculty Scavenger Hunt}

A Dozen plus One Potential Conversations/Connections about Teaching

- This game enables you to get acquainted with at least three resource people in this room, sharing with them a meaningful conversation about teaching.

- After you have talked with three people and obtained their signatures and email addresses, please drop the bottom portion of the sheet in the designated container.

- Continue talking with people and obtaining more signatures until time is called.

- Keep the top portion of this sheet for future reference.

Find someone who... and email address

1. Is working on or has completed a teaching or professional portfolio:

2. Can share an active learning technique they feel is particularly effective:

3. Uses one or more games in their teaching and can explain why they do so:

4. Finds that case studies are effective learning tools:

5. Can tell you about a classroom challenge they overcame:

6. Uses permanent or semi-permanent groups or teams in a class:

7. Has published an article in a teaching journal:

8. Has something unusual in their syllabus:

9. Has won a teaching award and can explain why they thought the judges awarded it: 
10. Has ever designed a poor exam or a poor exam question:

11. Considers themselves effective at motivating students to learn:

12. Can share an approach for learning student names rapidly:

13. Uses technology in a creative, effective way:

Your Name: 


\section{APPENDix 6.2}

Dear Joe/Josephine New-Faculty-Member:

Welcome to Innovative University! We encourage/require you to attend the Orientation meeting scheduled...

Because our college/university believes in active learning and student involvement, we intend at Orientation to "practice what we teach." Thus, rather than lecture to our captive audience, we prefer that you come prepared to share what you know about the institution, about higher education regulations and required practices, and about effective teaching. You will find enclosed materials [Listed] that will help you to become more knowledgeable.

To reinforce this knowledge and to add an element of fun and collegiality, we will use the final hour of the orientation session to play in pairs "Innovative University Bingo." Prizes are involved! You will literally be a key player not only during the game, but beforehand as well. Thus, we need you to submit by August XX two well-crafted questions to our Dean of Faculty, Dr. Ima Believer, preferably at her email address, ImaB@IU.edu, or alternatively, at her office address in the enclosed IU Faculty Handbook.

The questions should be of two types: 1) factual, with one right answer, and, 2) open-ended with alternative solutions. For the latter, you might want to write a one-paragraph mini-case, based on information/guidance in the faculty handbook. These questions should lead to productive paired discussions as options are weighed and then informative whole-group discussions as the possible solutions are evaluated by the person who submitted the question. [Note: Knowledgeable orientation staff will also share information when appropriate.]

These questions need to be suitable for a Bingo game format. Thus, they should not require rote memorization of overly complex material. They should, however, promote both learning and discussion about complex issues. They should also be questions predicated on what new faculty genuinely need to know. Please don't include anything obscure or irrelevant such as the name of the assistant librarian for technological frustrations. Be certain that you understand both your questions and the appropriate answers because you will be the expert/arbitrator called upon to approve/disapprove alternative answers, particularly with the open-ended questions. 
Because we will be enlarging the font size to prepare transparencies for the game and also using your questions to prepare a useful information sheet for all attendees, we ask that you follow a set format. Please indicate the following: The question, followed by your name underneath, and then the answer, preferably with a direct reference to the source (e.g., IU Faculty Handbook, p. 16). Sample questions from last year's orientation are below.

We look forward to seeing you soon!

Sincerely,

Dr. I. Love Orientation 